\title{
CIRCULACIÓN DE CEPAS DE LEPTOSPIRA EN ZONAS RURALES DE CIÉNAGA DE ORO, CÓRDOBA (COLOMBIA)
}

\section{CIRCULATION OF LEPTOSPIRA STRAINS IN RURAL AREAS FROM CIENAGA DE ORO, CORDOBA (COLOMBIA)}

\author{
Carlos Ensuncho $\mathrm{H}^{1}$, Virginia Rodríguez $\mathrm{R}^{2}$, Alfonso Calderón Range ${ }^{3}$ \\ Recibido para publicación: Febrero 20 de 2018 - Aprobado para publicación: Abril 17 de 2018
}

\begin{abstract}
RESUMEN
La leptospirosis es una zoonosis de distribución mundial, que causa grandes pérdidas económicas en animales de interés zootécnico y de impacto en salud pública. El objetivo general fue determinar la presencia de $L$. interrogans sensu lato en orina de bovinos y en fuentes de aguas en zonas rurales de Ciénaga de Oro, Córdoba (Colombia). Se tomaron 78 muestras de orina de vacas y 39 muestras de agua para cultivo bacteriológico y la determinación del gen $16 S$ rRNA de L. interrogans sensu lato. Aunque no se logró el aislamiento, se detectó por PCR $L$. interrogans sensu lato en tres orinas y en una muestra de aguas residuales. La determinación por PCR permitió confirmar la circulación de L. interrogans sensu lato. Conclusiones. Estas evidencias moleculares permiten inferir que en las zonas rurales de Ciénaga de Oro hay circulación activa de $L$. interrogans sensu lato en bovinos y fuentes de aguas.
\end{abstract}

Palabras clave: Ambiente, infección, leptospirosis, orina, zoonosis (DeCS).

\begin{abstract}
Leptospirosis is a zoonosis of worldwide distribution, which is cause of economic losses in farm animals with public health implications. The overall objective was to determine the presence of $L$. interrogans sensu lato in urine of cattle and water sources in rural areas from Córdoba (Colombia). 78 urine samples were collected from cows and 39 samples of water for bacteriological culture and determination of the $16 S r R N A$ gene from bacterial $L$. interrogans sensu lato. Although a definitive isolation was not achieved, L. interrogans sensu lato was detected by PCR in three urine samples and in one sample of waste water. Circulation of $L$. interrogans sensu lato was confirmed by means PCR. These molecular evidences suggested the possibility of circulation of L. interrogans sensu lato in cows and water sources from rural areas of Ciénaga de Oro.
\end{abstract}

Keywords: Environment, infection, leptospirosis, urine, zoonoses (DeCS).

\footnotetext{
${ }^{1}$ Médico veterinario y Zootecnísta M.Sc. Grupo de Investigación en Producción Animal Tropical (GIPAT), Facultad de Medicina Veterinaria y Zootecnia, Universidad de Córdoba.

${ }^{2}$ Bacterióloga. M.Sc. en Microbiología. Grupo de Investigaciones Microbiológicas y Biomédicas de Córdoba (GIMBIC), Programa Bacteriología Universidad de Córdoba.

${ }^{3}$ Médico veterinario y Zootecnísta, Ph.D. (c) Grupo de Investigación en Producción Animal Tropical (GIPAT), Facultad de Medicina Veterinaria y Zootecnia, Universidad de Córdoba Correspondencia: acalderoonr@correo.unicordoba.edu.co
} 


\section{INTRODUCCIÓN}

La leptospirosis es una enfermedad zoonótica, que infecta a humanos, mamíferos domésticos y salvajes en todo el mundo. Está enfermedad es de distribución mundial y de efectos mortales en los seres humanos (1). La infección se produce por leptospiras incluidas en el complejo patogénico denominado Leptospira interrogans sensu lato (2). El género Leptospira incluye al menos 21 especies dispuestas en tres grandes subgrupos basados en la filogenia del $16 S$ rRNA, hibridación ADN-ADN, patogenicidad, virulencia y características de crecimiento in vitro. Los grupos I y II, anteriormente denominados patógenos $y$ patógenos intermedios, respectivamente, incluyen 14 especies (nueve en el Grupo I y cinco en el Grupo II) y el grupo III compuesto por siete especies denominadas saprófitas. El grupo I patógenas incluye más de 250 serovares distintos y producen enfermedades en personas de gravedad variable, que van desde infeccione subclínicos a enfermedades graves y muerte (3). Los bovinos infectados son generalmente asintomáticos y pueden diseminar la bacteria por la orina (leptospiruria) durante largos periodos (4). El objetivo del presente estudio fue determinar la presencia de cepas patógenas de Leptospira interrogans sensu lato en orina de bovinos y en fuentes de aguas en zonas rurales del municipio de Córdoba (Colombia).

\section{MATERIALES Y MÉTODOS}

Zona de estudio. Se implementó en trece fincas ganaderas del sistema doble propósito, ubicadas en el municipio de Ciénaga deOro, departamento de Córdoba (Colombia) situado a $8^{\circ} 52^{\prime} 44^{\prime \prime} \mathrm{N}$ y $-75^{\circ} 42^{\prime} 8^{\prime \prime} \mathrm{O}$, en el caribe colombiano.

Tipo de estudio y muestreo. Por medio de un estudio no probabilístico y mediante un muestreo por conveniencia, donde se tuvo en cuenta acceso, facilidad de muestreo $y$ tratando de bajar los costos de laboratorio, se tomaron 78 muestras de orina de vacas a las cuales se les aplicó furosemida a una dosis de $40 \mathrm{mg} / \mathrm{kg}$ como dosis única por vía intravenosa para la micción, seguidamente se lavó y desinfectó el área perianal, esperando a que las vacas volviesen a orinar y con la ayuda de una manga obstétrica, se recolectó $30 \mathrm{ml}$ en frascos estériles. Las 39 muestras de agua trece de aguas no servidas como nacimientos, quebradas, pozos, tanques de almacenamiento; trece de bebederos naturales (caños y pequeñas cañadas) y trece de aguas servidas, se tomaron $30 \mathrm{ml}$ de agua mediante el uso de un tomador estéril desechable. Todas las muestras fueron depositadas en frascos estériles, identificados previamente y se conservaron en refrigeración hasta su procesamiento en el laboratorio.

Cultivos bacteriológicos. Las muestras de agua y orina se sembraron en medios líquidos y semisólidos de EMJH (Ellinghausen-McCulloughJohnson-Harris), enriquecido con suero de conejo al 1\%, y suplementado con y sin ácido nalidíxico y 5 fluoruracilo. Una porción de la muestra $(0,5 \mathrm{ml})$ se sembró directamente en los medios líquidos y semisólidos y otra fracción (2 $\mathrm{ml}$ ) se filtró en membrana con poro de $0.45 \mu$ y se inoculó 0,5ml en medios líquidos y semisólidos. Todos los cultivos se incubaron (Biobase, Modelo Augusta) entre $29^{\circ} \mathrm{C}$ y $30^{\circ} \mathrm{C}$ y el seguimiento se hizo quincenal durante cuatro meses.

Extracción del ADN. Las muestras de orina y agua se centrifugaron a 14000 revoluciones por cinco minutos y el sedimento obtenido de cada muestra se lavó con PBS. La extracción del material genético se hizo mediante un kit comercial (ID: 51306). El ADN se almacenó a $-20^{\circ} \mathrm{C}$. La detección de leptospiras patógenas por PCR se implementó utilizando los iniciadores PFA y PRA (5) que delimitan un fragmento de $357 \mathrm{pb}$ del gen 165 rRNA de leptospiras patógenas. La concentración final por $\mu \mathrm{l}$ de cada uno de los componentes de la mezcla de reacción de PCR fue: buffer de PCR $1 \mathrm{X}$, dNTPs $1.25 \mathrm{mM}, \mathrm{MgCl}_{2} 2 \mathrm{mM}$, iniciadores 
$1 \mathrm{uM}$, Taq DNA Pol 0.4U, 1 ul de ADN, en un volumen final de reacción de $25 \mu \mathrm{l}$. El perfil térmico utilizado fue $94^{\circ} \mathrm{C}$ por 5 minutos, 34 ciclos que constaron de: $94^{\circ} \mathrm{C}$ por 3 minutos, $64^{\circ} \mathrm{C}$ por 1 minuto, $72^{\circ} \mathrm{C}$ por 1 minutos y una extensión final a $72^{\circ} \mathrm{C}$ por 10 minutos.

Aspectos éticos. El estudio fue considerado de bajo riesgo por el Comité de Ética del Instituto de Investigaciones Biológicas del Trópico (IIBT), de la Facultad de Medicina Veterinaria Zootecnia, de la Universidad de Córdoba y los procedimientos de tomaron según las normas de las buenas prácticas de laboratorio y las normas éticas, técnicas y científicas, conforme a la Ley 84 (6).

\section{RESULTADOS}

De las 78 muestras de orinas cultivadas no se obtuvo crecimiento de leptospiras patógenas, durante cuatro meses de seguimiento; sin embargo, a partir de estas muestras se evidenció la presencia de $L$. interrogas sensu lato en tres muestras de orina por PCR (Figura1).

En las 39 muestras de aguas evaluadas en ninguna se logró obtener crecimiento de leptospiras patógenas, después de cuatro meses de seguimiento. Por PCR sólo en una muestra de agua se evidenció la presencia de L. interrogans sensu lato.

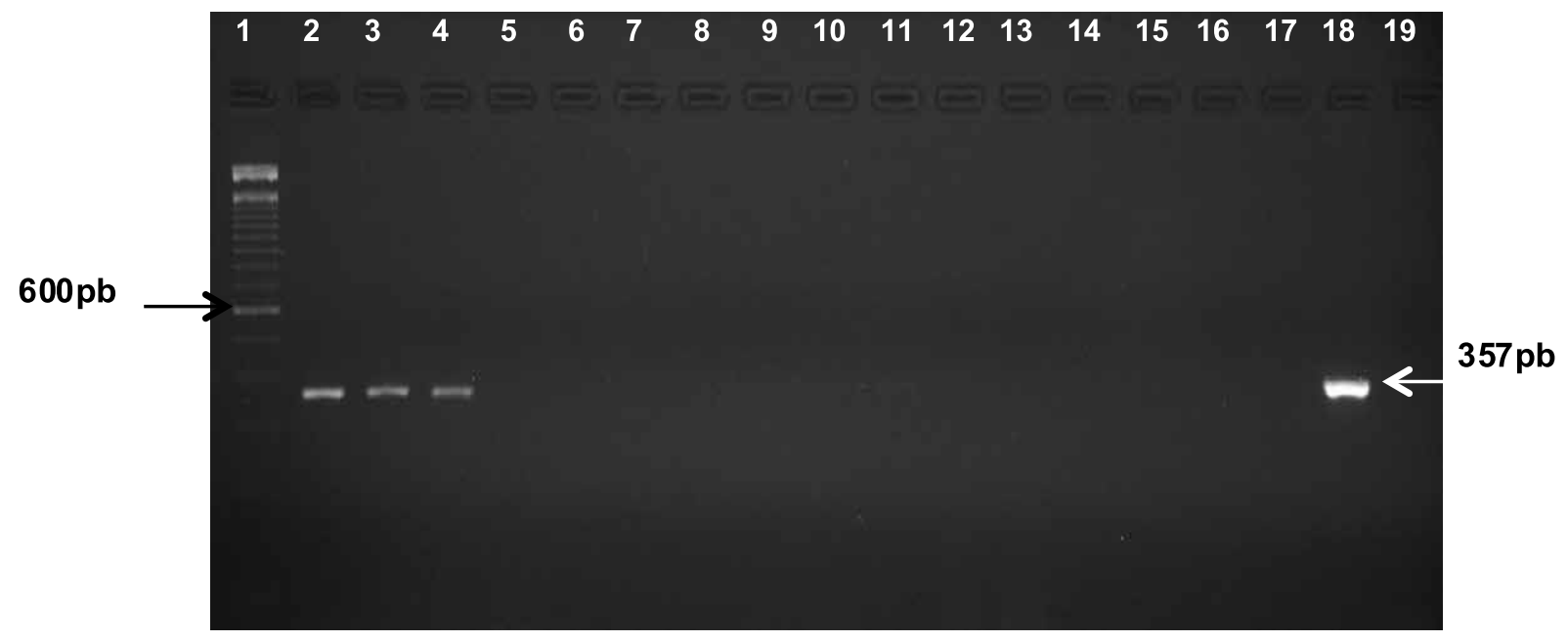

Figura 1. Detección por PCR de leptospiras patógenas usando iniciadores para el gen $16 S$ rRNA. Carril 1 : marcador de peso molecular 100pb Invitrogen. Carriles 2, 3, y 4: muestras de orina positiva para L. interrogans sensu lato. Carril 18: control positivo para L. interrogans sensu lato ADN serovar Australis. Carril 17: control negativo para $L$. interrogans sensu lato serovar Patoc. Carril 19: control de reactivos. Carriles 5, 6, 7, 8, 9, 10, $11,12,13,14,15$, y 16: Muestras de orina negativas para L. interrogans sensu lato.

\section{DISCUSIÓN}

Por PCR, se logró evidenciar la presencia de $L$. interrogans sensu lato en tres vacas. El hallazgo de genoma de $L$. interrogans sensu lato en las muestras de orina, sugiere el estado de portador crónico, pudiéndose considerar que la dinámica de transmisión de la leptospira en las fincas es activa. En Rio de Janeiro (Brazil) probando las orinas por PCR, se evidenció que el $33.6 \%$ fueron positivos (7) y en Sri Lanka se determinó el estado de portador de leptospiras patógenas en el $12.2 \%$ de los bovinos para flaB-PCR (8). 
En un predio se logró evidenciar molecularmente L. interrogans sensu lato en una muestra de agua y en una muestra de orina, podría sugerir una circulación entre diferentes especies. En el medio Sinú (Córdoba) por PCR ya se detectó $L$. interrogans sensu lato en dos muestras de agua. La primera cepa de fuentes de agua para beber y la segunda de aguas servidas o de desecho (9). Fuentes de aguas han sido implicadas en brotes de leptospirosis (10) y presencia de Leptospira spp. en fuentes de agua (11) y Leptospira spp. patógenas en fuentes de agua fresca (12).

A pesar de no aislar cepas, pero encontrar evidencias moleculares en las aguas, se considera que las aguas son un factor de riesgo en la transmisión de leptospiras, ya que por condiciones óptimas pueden sobrevivir en el agua y en el suelo húmedo por periodos de tiempo prolongados, sirviendo como fuente de infección tanto para humanos y animales (2). Ya se ha involucrado al agua en la transmisión de la leptospirosis, por ejemplo, en Israel se diagnosticó en viajeros que se relacionaron con actividades acuáticas en Asia (13), en Italia, se reportó la trasmisión en turistas (14), y en Irlanda se concluyó que el aumento en la incidencia se asoció al contacto con animales o deportes acuáticos (15).

\section{CONCLUSIONES}

En vacas y aguas, se comprobó la circulación activa de cepas de L. interrogans sensu lato por PCR.

\section{CONFLICTO DE INTERÉS}

Los autores declaran no tener ningún conflicto de interés.

\section{REFERENCIAS}

1. Ayral FC, BicoutDJ, Pereira H, Artois M, Kodjo A. Distribution of Leptospira serogroups in cattle herds and dogs in France. Am J Trop Med Hyg. 2014; 91:756-759.
2. Adler B, Peña MA. Leptospira and leptospirosis. Vet Microbiol. 2010; 140:287-296.

3. Lehmann JS, Matthias MA, Vinetz JM, Fouts DE. Leptospiral pathogenomics. Pathogens. 2014; 14;3(2):280-308.

4. Salgado M, Otto B. Sandoval E, Reinhardt G, Boqvist S. A cross sectional observational study to estimate herd level risk factors for Leptospira spp. serovars in small holder dairy cattle farms in southern Chile. BMC Vet Res. 2014; 10: 126.

5. Fearnley C, Wakeley PR, Gallego-Beltran J, Dalley C, Williamson S, Gaudie C, Woodward MJ. The development of a realtime PCR to detect pathogenic Leptospira species in kidney tissue. Res Vet Sci. 2008; 85(1):8-16.

6. Congreso Nacional de Colombia. 1989. Ley 84. Por la cual se adopta el Estatuto Nacional de Protección de los Animales $y$ se crean unas contravenciones y se regula lo referente a su procedimiento y competencia. República de Colombia, gobierno nacional. Diario Oficial 39120 de diciembre 27 de 1989. Bogotá.

7. Hamond C, Martins G, Lilenbaum W, Pinna M, Medeiros A. Infection by Leptospira spp. in cattle in a tropical region, Rio de Janeiro, Brazil. Am J Trop Med Hyg. 2015; $92(1): 210$.

8. Gamage C, Koizumi N, Perera AK, Muto M, Nwafor-Okoli C, Ranasinghe S, Kularatne SA, Rajapakse RP, Kanda K, Lee RB, Obayashi Y, Ohnishi M, Tamashiro H. Carrier status of leptospirosis among cattle in Sri Lanka: a zoonotic threat to public health. Transbound Emerg Dis. 2014; 61(1):91-96.

9. Calderón A, Rodríguez V, Mattar S, Arrieta G. Leptospirosis in pigs, dogs, rodents, 
humans, and water in an area of the Colombian tropics. Trop Anim Health Prod. 2014;46 (2):427-432.

10. Hochedez P, Escher M, Decoussy $H$, Pasgrimaud L, Martinez R, Rosine J, Théodose R, Bourhy $P$, Picardeau $M$, Olive C, Ledrans M, Cabie A. Outbreak of leptospirosis among canyoning participants, Martinique, 2011. Euro Surveill. 2013; 18(18):20472.

11. Wynwood SJ, Graham GC, Weier SL, Collet TA, Mckay DB, Craig SB. Leptospirosis from water sources. Pathog Glob Health. 2014; 108(7):334-338.

12. Andre-Fontaine G, Aviat F, Thorin C. Waterborne Leptospirosis: Survival and preservation of the virulence of pathogenic leptospira spp. in fresh water. Curr Microbiol. 2015; 71(1):136-42.
13. Leshem E, Segal G, Barnea A, Yitzhaki S, Ostfeld I, Pitlik S, Schwartz E. Travel-related leptospirosis in Israel: a nationwide study. Am J Trop Med Hyg. 2010; 82(3):459-463.

14. Lagi F, Corti T, Meli M, Pinto A, Bartoloni A. Leptospirosis acquired by tourists in Venice Italy. J. Travel Med. 2013; 20(2):128-130.

15. Garvey P, Connell J, O'flanagan D, Mckeown P. Leptospirosis in Ireland: annual incidence and exposures associated with infection, Epidemiol Infect. 2014; 142:847-855. 